\title{
SOCIOECONOMIC CHARACTERISTICS, ORAL CARE HABITS AND ORAL HEALTH-RELATED QUALITY OF LIFE AMONG THE PARENTS OF PRE-SCHOOL CHILDREN IN KLAIPE்DA
}

\author{
ANDRUŠKIENĖ Jurgita ${ }^{1}$, BARSEVIČIENĖ Šarūné ${ }^{1}$, \\ DVARIONAITÉ Lijana ${ }^{1}$, GRUBLIAUSKIENĖ Jūraté ${ }^{2}$, MAŽIONIENĖ Asta ${ }^{1}$ \\ ${ }^{1}$ Klaipeda State University of Applied Sciences, Klaipeda, Lithuania \\ ${ }^{2}$ Klaipeda University, Klaipeda, Lithuania
}

\begin{abstract}
There is a lack of data about oral health-related quality of life (OHRQoL) among the parents of pre-school children, especially in Lithuania and the relationships among socio-economic status, oral care habits and OHRQoL. Research questions: is OHRQoL influenced by socioeconomic status or oral care habits? Research focus - oral health-related quality of life among the parents of pre-school children. The aim of this study was to analyze the relationships among socioeconomic status, oral care habits and oral helath-related quality of life among the parents of pre-school children in Klaipeda. The study sample consisted of 375 parents (mother or father) of pre-school children. The questionnaire survey was conducted at randomly selected 23 kindergartens in Klaipeda city. The questionnaire consisted of sociodemographic and oral care habits questions. All the participants were examined by self-administered OIDP questionnaire, which measured oral impacts on physical, psychological and social aspects of daily performances. The highest overall impact on OHRQoL among the parents of pre-school children was observed in the domain of Carrying out major work or role (73.0), the lowest one in the Eating and enjoying food (25.74) domain. Mean OIDP score was significantly higher among the parents whose socioeconomic status was low (35.44), reflecting poorer OHRQoL, as compared with high (8.07) socioeconomic status. Parents with poor oral care habits significantly more frequently were affected (79.2\%) in Smiling, laughing domain, as compared to the parents whose oral care habits were good (20.8\%). Lower socioeconomic status and poorer oral care habits were related with worsened oral health-related quality of life, especially in the area of psychological performances.
\end{abstract}

Keywords: Oral care habits; Oral health-related quality of life; Parents. 


\section{Background}

Oral health-related quality of life tools measure the extent to which oral diseases affect an individual's well-being, determine the subjective functional and psycho-social impacts of oral diseases and facilitate holistic approach to oral health (Chattopadhyay, 2011; Shearer et al., 2007; Inglehart \& Bagramian, 2002; Geurink, 2011). Clinical indicators alone do not reveal the full impact of oral conditions on the psychosocial wellbeing of a person (McGrath et al., 2004). Assessing social, psychological and economic impacts can be used to identify population subgroups that need to be targeted for health promotion and disease prevention efforts (Oral Health in America, 2000). Sociodental approach combining OHRQoL with the standard clinical measures comes closer to current concepts of health than the traditional standard approach. There was a significant difference between the standard and the sociodental needs assessment approaches, with sociodental needs being $60 \%$ lower than those identified by the traditional approach (Gherunpong et. al., 2006).

OHRQoL tools can be used effectively in preventive program planning and outcome evaluation. Planning is a systematic approach to defining the problem, setting priorities, developing specific goals and objectives, and determining alternative strategies and a method of implementation. Outcome evaluation provides several benefits such as tracking progress, making decisions and/or improving the quality of initiatives and efforts, creating accountability and marketing successful efforts (Chattopadhyay, 2011).

Parents of pre-school children is an important target group for preventive interventions, because parents play the central role in ensuring their child's health care (Talekar et al., 2005). Studies show that parental attitudes toward children's oral health are significantly associated with their own oral health behavior and understanding the importance of development of oral hygiene skills of children (Vanagas et al., 2009; Al Ansari et al., 2003). Mother's young age, parents' cohabitation, rural dwelling, parents' poor dental hygiene habits, all those factors were proved as the main factors related with incidence of children's caries (Matilla et al., 2000). Higher parents' education is related with better oral care of their children (Saied-Moallemi et al., 2008). Studies demonstrate that socioeconomic situation in the family and home environment significantly influences children's OHRQoL (Sanders and Spencer, 2005; Paula et al., 2012).

Social conditions in families are associated with self-perception of the impact of oral health on quality of life - individuals with low education and income have negative impressions about their oral healthrelated quality of life (Cohen-Carneiro et al., 2011). The National Health and Nutritional Examination Survey (NHANES), conducted in a national probability sample, results demonstrated that a lack of 
financial support reduced OHRQoL, but social support did not, persons aged 24-44 and 45-64 had significantly lower OHRQoL, but persons older than 65 years, did not (Maida, Marcus et al., 2013). Findings have shown that individuals with low incomes report higher psychosocial impacts (Locker \& Quiñonez, 2009) and that there are gender (Einarson et al., 2009) and age (Steele et al., 2004) differences in perception of OHRQoL.

Dental health behavior, use of floss and toothpicks and oral rinsing were not associated with having problems related to oral health-related quality of life in the representative sample of adult persons in Norway (Dahl et al., 2011). Recent studies indicate that better health-related behaviors and routine dental attendance have a protective effect on OHRQoL (Almoznino et al., 2015).

Socioeconomic inequalities in oral impacts on daily life were compared among 21 European countries with different welfare state regimes (Scandinavian, Anglo-Saxon, Bismarckian, Southern, and Eastern). It was concluded that welfare state regimes might influence the relationship between knowledge-related resources and oral impacts on daily life (Guarnizo-Herreño et al., 2014). The clinical aspects of oral health have been widely investigated in clinical studies. There is a lack of studies in Lithuania investigating oral health-related quality of life in the community and in clinical studies. The search results in PubMed, using keyword "oral health-related quality of life" showed, there were 3 scientific papers published during the period of 5 years, concerning oral health-related quality of life as an object of investigation in the Lithuanian clinical population. The lingual and cultural adaptation of the OIDP instrument was performed several years ago in Klaipeda State University of Applied Sciences (former title Klaipeda State College). Lithuanian version of the OIDP questionnaire showed valid and reliable psychometric properties, confirming its appropriateness to measure oral health-related quality of life of young Lithuanian people. The strongest correlation was assessed between Contact and Smiling domains, as well as Major Work and Emotions. The weakest correlation was identified between Contact and Physical Activity domains (Andruškienė \& domavičienè, 2012). This survey will help to obtain the first day in Lithuania about the associations among socioeconomic characteristics, oral care habits and oral health-related quality of life among the parents of pre-school children. Discovering the relationships may enable the development of preventive interventions which will improve oral health-related quality of life in the community.

The aim of this study was to analyze the relationships among socioeconomic status, oral care habits and oral helath-related quality of life among the parents of pre-school children in Klaipeda. 


\section{Methodology}

\section{Sample}

The study sample consisted of 375 parents (mother or father) of pre-school children. The questionnaire survey was conducted at randomly selected 23 kindergardens in Klaipeda city. The inclusion criteria was the Lithuanian language used as the main in the kindergarten. The parents filled in questionnaires during the educational event held by the collaborating institutions Klaipeda City Public Health Bureau and Klaipeda State University of Applied Sciences. The greater part of the parents were 25-44 years old, $82.8 \%$ of mothers, and $85.7 \%$ of fathers. More than the half $(59.7 \%)$ of mothers and $44.0 \%$ of fathers had higher education. The major part of the mothers (78.9\%) and the fathers $(94.2 \%)$ were employed at the survey time, $81.1 \%$ lived in a full family. Only $20.8 \%$ of the respondents had a family income higher than $500 €$ per month. The respondents were divided to the groups according to the socioeconomic status. When both parents in the family were employed, lived in family and had high income for one family member, the respondent was ascribed to the group of High socioeconomic status $(\mathrm{n}=168,44.8 \%)$. When at least one of the parents was unemployed or did not live in family or had low family income, were ascribed to the group of Low socioeconomic status $(\mathrm{n}=207,55.2 \%)$. The respondents were divided to the groups according to oral care habits. Persons were defined as having Good oral care habits ( $\mathrm{n}=129$, $34.4 \%$ ) if they performed regular tooth brushing ( $\geq 2$ times per day), changed toothbrush regularly (not less than once per three months) and used additional oral care tools (interproximal brushes, oral rinses or tongue scraper) and the duration of tooth brushing was $\geq 3$ minutes. Respondents were defined as having Poor oral care habits if they did not meet at least one criteria for defining them to the group of persons having good oral care habits $(n=246,65.6 \%)$.

\section{Methods}

All statistical analyses were performed using the SPSS software, PC version 20. Descriptive and analytical methods were used. Statistical significance was assumed when $\mathrm{p}<0.05$ or when the $95 \%$ confidence interval excluded 1.0. Chi square criterion was used to compare prevalence of oral impacts among sociodemographic and oral care habits groups. Comparison of means between sociodemographic groups was carried out using Student's t test. 


\section{DE}

DOI: $10.1515 /$ arhss-2016-0004

Applied Research In Health And Social Sciences: Interface And Interaction, Vol. 13, No. 1, 2016

\section{Tools}

In this study, eleven physical, psychological and social aspects of daily performances were questioned using OIDP (Oral Impacts on Daily Performances) questionnaire (Gherunpong et al., 2006). The participants were asked whether, during the past six months, they had experienced any difficulties with the following activities due to problems with their mouth or teeth (or dentures): 1. Eating and enjoying food; 2. Speaking and pronouncing clearly; 3. Cleaning teeth (or dentures); 4. Performing light physical activity; 5. Sleeping; 6. Relaxing; 7. Smiling, laughing; 8. Maintaining emotional state (for example becoming more easily upset than usual); 9. Going out (for example to shop or visit someone); 10. Carrying out major work or role; 11. Enjoying contact with people. Respondents who answered 'yes' to any item were asked whether the problems were regular or only for part of the period. The frequency was rated 1-5: for those affected on a regular basis from 'less than once a month' to 'every day or nearly every day', and for those affected only part of the period from ' 5 days or less' to 'more than 3 months'. Finally, the severity of the effect on everyday life was examined with the following ratings: 'no effect' (0), 'a very minor effect' (1), 'a fairly minor effect' (2), 'a moderate effect' (3), 'a fairly severe effect' (4) or 'a very severe effect' (5). Eleven performance scores were calculated by multiplying frequency and severity scores. To obtain the OIDP score for an individual (OIDP score), the sum of the eleven scores was divided by the possible maximum performance scores: eleven performances $\times$ maximum frequency score $(5) \times$ maximum severity score $(5)=275$, and multiplied by 100 to provide a percentage score, equaling the OIDP score. The OIDP score was dichotomized for the validity analyses: having 'at least one daily performance affected' versus 'no daily performance affected'. The median value of the OIDP score was used as an alternative dichotomization cut-off point for the group that reported at least one daily performance affected. Evaluation of total OIDP scoring results: value $0.0-12.0$ considered as low overall OIDP score, 12.1 - 21.0 - moderate score, 21.1 - 100.0 - high score.

Sociodemographic questions about the age, education, employment situation, and family status, income per month, living area, and number of the children in family, children's age and gender were included in the questionnaire. There were also questions on how often the parents brushed their teeth and their children's teeth, how often they used interproximal brushes, oral rinses or tongue scrapers, how often the parents and the children visited the dentist during a period of the last 5 years. There was a question about the parents' perception of their child's oral health. 
DOI: 10.1515/arhss-2016-0004

Applied Research In Health And Social Sciences: Interface And Interaction, Vol. 13, No. 1, 2016

\section{Ethics}

Ethics Standard informative letter was used, in which respondents were asked to sign and return if they do or do not wish to participate in the study. In the letter respondents were shortly informed about study objectives and confidentiality of the data. Concerning confidentiality all questionnaires were identified by a number, which was kept separate from the personal identification of participants. The number corresponding to each participant was only available to the research group members. The study was approved by the Bioethics Committee of Klaipeda State University of Applied Sciences.

\section{Findings}

Table 1 demonstrates the frequency and severity oral impacts on OHRQoL. The highest mean of individual OIDP score among the parents of pre-school children was observed in the domain of Carrying out major work or role (73.0), the lowest one in the Eating and enjoying food (25.74) domain. The highest percent of persons affected was in the domain Eating and enjoying food (17.6\%), the lowest one in the domain Performing light physical activity (2.9\%). The greatest mean of frequency of those affected was in the domain Speaking and pronouncing clearly (3.0) and Smiling, laughing (3.0). The most severe effect was observed on the domain Enjoying contact with people (3.08) (see Table 1).

Table 1

Oral impacts on oral health-related quality of life domains

\begin{tabular}{|l|c|c|c|c|c|}
\hline $\begin{array}{c}\text { Oral health-related quality } \\
\text { of life domains }\end{array}$ & $\begin{array}{c}\text { Number of } \\
\text { persons } \\
\text { affected } \\
\text { N }\end{array}$ & $\begin{array}{c}\text { Percent of } \\
\text { persons } \\
\text { affected }\end{array}$ & $\begin{array}{c}\text { Mean (SD) } \\
\text { frequency of } \\
\text { those } \\
\text { affected }\end{array}$ & $\begin{array}{c}\text { Mean (SD) } \\
\text { severity of } \\
\text { those } \\
\text { affected }\end{array}$ & $\begin{array}{c}\text { Mean (SD) } \\
\text { individual } \\
\text { OIDP score }\end{array}$ \\
\hline Physical performances & 66 & 17.6 & $2.02(1.14)$ & $2.12(1.09)$ & $25.74(38.28)$ \\
\hline Eating and enjoying food & 18 & 4.8 & $3.00(1.37)$ & $2.89(1.41)$ & $69.67(49.93)$ \\
\hline $\begin{array}{l}\text { Speaking and pronouncing } \\
\text { clearly }\end{array}$ & 36 & 9.6 & $2.75(1.56)$ & $2.42(1.38)$ & $36.39(47.25)$ \\
\hline Cleaning teeth & 11 & 2.9 & $1.82(1.40)$ & $1.91(1.45)$ & $60.64(59.61)$ \\
\hline $\begin{array}{l}\text { Performing light physical } \\
\text { activity }\end{array}$ & 17 & 4.5 & $2.12(1.05)$ & $2.88(1.11)$ & $47.06(44.6)$ \\
\hline Psychological performances
\end{tabular}


DOI: 10.1515/arhss-2016-0004

Applied Research In Health And Social Sciences: Interface And Interaction, Vol. 13, No. 1, 2016

\begin{tabular}{|l|c|c|c|c|c|}
\hline Relaxing & 20 & 5.3 & $2.15(1.31)$ & $2.30(1.22)$ & $48.05(54.33)$ \\
\hline Smiling, laughing & 48 & 12.8 & $3.00(1.44)$ & $2.98(1.25)$ & $33.06(39.20)$ \\
\hline $\begin{array}{l}\text { Maintaining usual emotional } \\
\text { state }\end{array}$ & 24 & 6.4 & $2.21(1.25)$ & $2.54(1.18)$ & $45.46(46.62)$ \\
\hline Social performances & 16 & 4.3 & $2.19(1.22)$ & $2.38(1.09)$ & $57.0(49.72)$ \\
\hline Going out & 13 & 3.5 & $2.46(1.33)$ & $3.00(1.35)$ & $73.0(55.64)$ \\
\hline $\begin{array}{l}\text { Carrying out major work or } \\
\text { role }\end{array}$ & & & & & $54.44(47.29)$ \\
\hline Enjoying contact with people & 27 & 7.2 & $2.77(1.48)$ & $3.08(1.38)$ & \\
\hline
\end{tabular}

$\mathrm{SD}$ - standard deviation

Mean individual OIDP scores were compared according to the socioeconomic characteristics in Table 2. Unemployed persons had significantly higher mean OIDP scores as compared with employed ones, 66.5 vs $18.18, \mathrm{p}=0.002$. Persons who lived together in families had significantly lower OIDP score (20.28), as compared to those who were single or lived separately (89.67), $\mathrm{p}=0.001$. Mean individual OIDP score was significantly $(\mathrm{p}=0,027)$ higher among the parents whose socioeconomic status was low (35.44), reflecting poorer OHRQoL, as compared to high (8.07) socioeconomic status (see Table 2).

Table 2

Mean individual OIDP scores and socioeconomic characteristics

\begin{tabular}{|c|c|c|}
\hline Characteristics & Mean individual OIDP score (SD) & $\mathbf{p}$ \\
\hline \multicolumn{3}{|l|}{ Mother's education } \\
\hline High/Low & $23.80(37.06) / 28.86(39.54)$ & 0.692 \\
\hline \multicolumn{3}{|l|}{ Father's education } \\
\hline High/Low & $29.28(43.31) / 22.48(32.55)$ & 0.579 \\
\hline \multicolumn{3}{|l|}{ Mother's age } \\
\hline$\leq 34 />34$ & $24.00(36.83) / 26.86(38.87)$ & 0.817 \\
\hline \multicolumn{3}{|l|}{ Father's age } \\
\hline$\leq 34 />34$ & $24.0(36.83) / 26.86(38.87)$ & 0.817 \\
\hline \multicolumn{3}{|l|}{ Mother's employment } \\
\hline Employed/Unemployed & $22.37(34.69) / 36.44(46.44)$ & 0.330 \\
\hline \multicolumn{3}{|l|}{ Father's employment } \\
\hline Employed/Unemployed & $18.18(27.36) / 66.50(59.51)$ & 0.002 \\
\hline \multicolumn{3}{|l|}{ Family status } \\
\hline Live in family/Live separately & $20.28(28.12) / 89.67$ (79.10) & 0.001 \\
\hline
\end{tabular}


DOI: 10.1515/arhss-2016-0004

Applied Research In Health And Social Sciences: Interface And Interaction, Vol. 13, No. 1, 2016

\begin{tabular}{|c|c|c|}
\hline \multicolumn{3}{|l|}{ Family income } \\
\hline High/Low* & $17.83(41.14) / 32.29(33.71)$ & 0.235 \\
\hline \multicolumn{3}{|l|}{ Living area } \\
\hline City/Suburbs & $27.03(38.72) / 8.67$ (7.37) & 0.423 \\
\hline \multicolumn{3}{|l|}{ Socioeconomic status } \\
\hline High/Low** & $8.07(5.50) / 35.44(43.97)$ & $\mathbf{0 . 0 2 7}$ \\
\hline \multicolumn{3}{|l|}{ Number of children in a family } \\
\hline$<3 / \geq 3$ & $26.13(41.71) / 23.89$ (19.45) & 0.877 \\
\hline \multicolumn{3}{|l|}{ Child's gender } \\
\hline Male/Female & $17.89(17.93) / 32.24(47.98)$ & 0.239 \\
\hline \multicolumn{3}{|l|}{ Child's age } \\
\hline$<4 / \geq 4$ & $13.00(-) / 25.95(37.97)$ & 0.738 \\
\hline \multicolumn{3}{|l|}{ Parents $^{6}$ oral care habits } \\
\hline Good/Poor $^{* * * *}$ & $8.33(9.13) / 33.30(42.71)$ & 0.054 \\
\hline \multicolumn{3}{|l|}{ Visits to the dentist } \\
\hline Yes/No & $24.32(37.13) / 75.00(-)$ & 0.186 \\
\hline \multicolumn{3}{|l|}{ Frequency of the visits to dentist } \\
\hline$<$ Once a year or $l \geq$ Once a year & $23.30(24.35) / 26.41(41.45)$ & 0.824 \\
\hline \multicolumn{3}{|l|}{ Has the child visited the dentist? } \\
\hline Yes /No & $25.62(37.53) / 0.00$ & - \\
\hline \multicolumn{3}{|l|}{$\begin{array}{l}\text { Child's age at the first visit to the } \\
\text { dentist }\end{array}$} \\
\hline$<3$ years $/ \geq 3$ years & $25.92(48.75) / 25.46(31.62)$ & 0.972 \\
\hline \multicolumn{3}{|l|}{ Frequency of the child's visits } \\
\hline$<$ Once a year or $/ \geq$ Once a year & $15.50(10.37) / 27.45(40.41)$ & 0.480 \\
\hline \multicolumn{3}{|l|}{$\begin{array}{l}\text { Parents perception of their child's oral } \\
\text { health }\end{array}$} \\
\hline Healthy/Unhealthy & $0.00 / 25.62(37.53)$ & - \\
\hline
\end{tabular}

*- Small income: $\leq 250$ Euro for 1 family member per month

**- High socioeconomic status - both parents were employed, living in the family, income for one family member is high

*** - Good oral care habits - regular toothbrushing ( $\geq 2$ times per day) and regular change of the toothbrush (not less than once per three months) and additional (interproximal brushes or oral rinses or tongue scraper) and duration of toothbrushing $\geq 3$ minutes $\mathrm{SD}$ - standard deviation

The prevalence of oral impacts on daily performances among the parents having good and poor oral care habits is presented in Table 3. Parents with poor self-assessed oral care habits significantly more 
frequently were affected (79.2\%) in Smiling, laughing domain, as compared to the parents whose oral care habits were $\operatorname{good}(20.8 \%), \mathrm{p}=0.034$.

Table 3

Prevalence (\%) of oral impacts on daily performances among the parents having good and poor oral care habits

\begin{tabular}{|c|c|c|c|}
\hline $\begin{array}{c}\text { Oral health-related quality } \\
\text { of life domains }\end{array}$ & $\begin{array}{c}\text { Good oral health care } \\
\text { habits }^{*} \\
\text { Number of persons } \\
\text { affected } \\
\text { n=129 } \\
\text { N (\%) }\end{array}$ & $\begin{array}{c}\text { Poor oral health care } \\
\text { habits }^{* *} \\
\text { Number of persons affected } \\
\mathbf{n}=246 \\
\mathrm{~N}(\%)\end{array}$ & $\begin{array}{c}\text { Chi square } \\
\text { test / } \\
\text { p }\end{array}$ \\
\hline Eating and enjoying food & $24(36.4)$ & $42(63.6)$ & $0.137 / 0.711$ \\
\hline $\begin{array}{l}\text { Speaking and pronouncing } \\
\text { clearly }\end{array}$ & $3(16.7)$ & $15(83.3)$ & $2.635 / 0.105$ \\
\hline Cleaning teeth & $12(33.3)$ & $24(66.7)$ & $0.020 / 0.887$ \\
\hline $\begin{array}{l}\text { Performing light physical } \\
\text { activity }\end{array}$ & $3(27.3)$ & $8(72.7)$ & $0.255 / 0.614$ \\
\hline Sleeping & $5(29.4)$ & $12(70.6)$ & $0.196 / 0.658$ \\
\hline Relaxing & $6(30.0)$ & $14(70.0)$ & $0.181 / 0.670$ \\
\hline Smiling, laughing & $10(20.8)$ & 38 (79.2) & $4.490 / 0.034$ \\
\hline $\begin{array}{l}\text { Maintaining usual emotional } \\
\text { state }\end{array}$ & $5(20.8)$ & $19(79.2)$ & $2.043 / 0.153$ \\
\hline Going out & $3(18.8)$ & $13(81.2)$ & $1.814 / 0.178$ \\
\hline $\begin{array}{l}\text { Carrying out major work or } \\
\text { role }\end{array}$ & $3(23.1)$ & $10(76.9)$ & $0.743 / 0.389$ \\
\hline Enjoying contact with people & $8(29.6)$ & $19(70.4)$ & $0.273 / 0.601$ \\
\hline
\end{tabular}

\section{Discussion}

Epidemiologic data about oral health-related oral health in relation to quality of life in the general population of young adults in Lithuania is limited. Our study results were different from the survey, which was conducted among the young adults, aged 35-44 years, employees of 4 universities in Lithuania, $79.0 \%$ of them were females, and $82.0 \%$ had university education (Sakalauskiene et al., 2011). Our study results, as compared to university employees' survey, demonstrated lower self-assessed 
satisfaction of own oral health status. Less than a half (34.4\%) of the parents of pre-school children in Klaipeda evaluated their own oral health status as good, while even $73.0 \%$ of young adult working in Lithuanian universities, assessed their dental health as very good or good. The differences of the results could be influenced by the differences in sample size and methodological issues. Our study results showed similar results, regarding oral care habits. More than one third (34.4\%) of the parents of preschool children in and $55.0 \%$ of young adults employed at Lithuanian universities, were defined as having good oral care habits.

Our study results confirmed that persons having poor oral care habits had more impacts on OHRQoL, especially on psychological performances (smiling, laughing), as compared to those who had good oral care habits. These findings repeated the results of other study (Almoznino et al., 2015) indicating that better health-related behaviors, including no alcohol consumption, regular physical activity, fewer smoking pack years and routine dental attendance had a protective effect on OHRQoL amog the individuals presenting for dental treatment. Swedish scientists (Johansson and Östberg, 2015) confirmed the OHRQoL of young adults was dependent not only on their own experiences of oral health during childhood and their received dental care but also on their present self-perceived oral health, oral health habits, and social life, together with their expectations of future oral health.

The economic situation for young people has become more insecure during the last decades, due to uncertain labor market, leading to high levels of unemployment, longer education and delay setting into marriage and parenthood, mainly because of economic circumstances (Arnett, 2007).

Our study results demonstrated the relationship between socioeconomic situation and OHRQoL, because the parents having low socioeconomic status (55.2\%), had significantly higher individual OIDP score as compared to parents who had high socioeconomic status (44.8\%). These findings are in line with other surveys performed in England, Wales, Northern Ireland which showed that reduced OHRQoL was more prevalent among the persons with socio-economic disadvantages, e.g. lower income and education, unemployment, a lack of social support, especially among young age persons (Sischo \& Broder, 2011; Guarnizo-Herreño et.al., 2014). Even in Sweden, the country where oral health is good among young people, it is still poor in socio-economically weak groups (Nordenram, 2012).

Preventive programs must be oriented towards the parents of pre-school children, because the parental attitudes toward children's oral health were significantly associated with their own oral health behavior and understanding the importance of development of oral hygiene skills in their children (Vanagas et al., 2009). The results of our study, despite some methodological limitations, could be used as the scientific 
basis while planning the activities of public health bureaus, inform public health policy and help reduce oral health inequalities.

\section{Conclusions}

The highest impact on oral health-related quality of life among the parents of pre-school children in Klaipeda was observed in the domain of Carrying out the major work or role, however the most severe effect was established on the domain Enjoying contact with people. Lower socioeconomic status and poorer oral care habits were related with worsened oral health-related quality of life, especially in the area of psychological performances. Parents with poor self-assessed oral care habits significantly more frequently were affected in Smiling, laughing domain, as compared to the parents whose oral care habits were good.

\section{Acknowledgements}

We thank the administration of the Klaipeda City Public Health Bureau for the support of educational activities in the kindergartens. We also thank dental hygienists E. Narutavičiūtè, A. Rudžianskienė, L. Dvarionaitè, E. Diržinauskienė and dentist A. Staražinskienè who did the educational work in the kindergardens in Klaipėda.

\section{References}

Al Ansari, J., Honkala, E., \& Honkala, S. (2003). Oral health knowledge and behavior among male health sciences college students in Kuwait. BioMed Central Public Health Journal, 3(2). Available at: http://bmcoralhealth.biomedcentral.com/articles/10.1186/1472-6831-3-2 (Accessed on 12/01/2016).

Almoznino, G., Aframian, D. J., Sharav, Y., Sheftel, Y., Mirzabaev, A., \& Zini, A. (2015). Lifestyle and dental attendance as predictors of oral health-related quality of life. Oral Diseases, 21(5), 659-666.

Andruškienė, J., \& Adomavičienè, D. (2012). Oral impacts on daily performances among students. Applied Research in Health and Social Sciences: Interface and Interaction, 1(9), 54-61.

Arnett, J. J. (2007). Emerging adulthood: What is it, and what is it good for? Child Development Perspectives, 1, 6873.

Chattopadhyay, A. (2011). Oral Health Epidemiology: Principles and Practice. USA: Jones and Bartlett Publishers.

Cohen-Carneiro, F., Souza-Santos, R., \& Rebelo, M. A. (2011). Quality of life related to oral health: contribution from social factors. Ciência \& Saúde Coletiva, 16(1), 1007-1015.

Dahl, K. E., Wang, N. J., Skau, I., \& Ohrn, K. (2011). Oral health-related quality of life and associated factors in Norwegian adults. Acta Odontologica Scandinavica, 69(4), 208-214. 
Einarson, S., Gerdin, E. W., \& Hugoson, A. (2009). Oral health impact on quality of life in an adult Swedish population. Acta Odontologica Scandinavica, 67(2), 85-93.

Geurink, K.V. (2011). Community Oral Health Practice for the Dental Hygienist. USA: Elsevier Saunders.

Gherunpong, S., Sheiham, A., \& Tsakos, G. (2006). Validation of an English version of the Child-OIDP index, an oral health-related quality of life measure for children. Health and Quality of Life Outcomes, 4(38), 1-7.

Guarnizo-Herreno, C. C., Watt, R. G., Pikhart, H., \& Tsakos, G. (2014). Inequalities in oral impacts and welfare regimes: analysis of 21 European countries. Community Dentistry and Oral Epidemiology, 42(6), 517-525.

Guarnizo-Herreno, C. C., Watt, R. G., Fuller, E., Steele, J. G., Shen, J., Morris, S., Wildman, J., \& Tsakos, G. (2014). Socioeconomic position and subjective oral health: findings for the adult population in England, Wales and Northern Ireland. BioMed Central Public Health Journal, 14, 827. Available at: https://www.ncbi.nlm.nih.gov/pmc/articles/PMC4240880/ (Accessed on 12/01/2016).

Inglehart, M. R., \& Bagramian, R. A. (2002). Oral Health-related Quality of Life. Illinois: Quintessence Publishing Co Inc.

Johansson, G., \& Östberg, A.L. (2015). Oral health-related quality of life in Swedish young adults. International Journal of Qualitative Studies on Health and Well-being, 10: 27125. Available at: http://europepmc.org/abstract/pmc/pmc4462826 (Accessed on 12/01/2016).

Locker, D., \& Quiñonez, C. (2009). Functional and psychosocial Impacts of oral disorders in Canadian adults: a national population survey. Journal of the Canadian Dental Association, 75(7), 521.

Maida, C. A., Marcus, M., Spolsky, V. W., Wang, Y., \& Liu, H. (2013). Socio-behavioral predictors of self-reported oral health-related quality of life. Quality of Life Research, 22(3), 559-566.

Matilla, M. L., Rautava, P., Sillanpää, M., \& Paunio, P. (2000). Caries in five-year-old children and associations with family-related factors. Journal of Dental Research, 79(3), 875-881.

McGrath, C., Broder, H., \& Wilson-Genderson, M. (2004). Assessing the impact of oral health and the life quality of children: implications for research and practice. Community Dentistry and Oral Epidemiology, 32(2), 81-85.

Nordenram, G. (2012). Dental health. Health in Sweden: The public health report 2012. Scandinavian Journal of Public Health, 40(9), 42-70.

Oral Health in America (2000). A Report of the Surgeon General. MD: US Department of Health and Human Services, National Institutes of Health. Available at: https://profiles.nlm.nih.gov/ps/access/nnbbjv.pdf (Accessed on 12/01/2016).

Paula, J. S., Leite, I. C., Almeida, A. B., Ambrosano, G. M., Pereira, A. C., \& Mialhe, F. L. (2012). The influence of oral health conditions, socioeconomic status and home environment factors on schoolchildren's selfperception of quality of life. Health and Quality of Life Outcomes, 13;10(6). Available at: https://www.ncbi.nlm.nih.gov/pubmed/22244092 (Accessed on 12/01/2016).

Sakalauskiene, Z., Vehkalahti, M. M., Murtomaa, H., \& Mačiulskienė, V. (2011). Factors related to gender differences in toothbrushing among Lithuanian middle-aged university employees. Medicina, 47(3), 180-186. 
Saied-Moallemi, Z., Virtanen, J. I., Ghofranipour, F., \& Murtomaa, H. (2008). Influence of mothers' oral health knowledge and attitudes on their children's dental health. European Archives of Paediatric Dentistry, 9(2), 79-83. .

Sanders, A. E., \& Spencer, A. J. (2005). Childhood circumstances, psychosocial factors and the social impact of adult oral health. Community Dentistry and Oral Epidemiology, 33(5), 370-337.

Shearer, D. M., Macleod, R. J., \& Thomson, W. M. (2007). Oral health-related quality of life: an overview for the general dental practitioner. The New Zealand Dental Journal, 103(4), 82-87.

Sischo, L., \& Broder, H. L. (2011). Oral Health-Related Quality of Life: What, Why, How and Future Implications. Journal of Dental Research, 90(11), 1264-1270.

Steele, J. G., Sanders, A. E., Slade, G. D., Allen, P. F., Lahti, S., Nuttall, A. J. (2004). How do age and tooth loss affect oral health impacts and quality of life? A study comparing two national samples. Community Dentistry and Oral Epidemiology, 32(2), 107-114.

Talekar, B. S., Rozier, R. G., Slade, G. D., \& Ennett, S. T. (2005). Parental perceptions of their preschool-aged children's oral health. Journal of the American Dental Association, 136(3), 364-372.

Vanagas, G., Milašauskienè, Ž., Grabauskas, V., \& Mickevičienè, A. (2009). Associations between parental skills and their attitudes toward importance to develop good oral hygiene skills in their children. Medicina, 45(9), 718-723. 